\title{
Disposable solid state probe for optical screening of chlorpromazine
}

\author{
Joana Rafaela Lara Guerreiro • \\ Maria Goreti Ferreira Sales
}

\begin{abstract}
We are presenting a simple, low-cost and rapid solid-state optical probe for screening chlorpromazine (CPZ) in aquacultures. The method exploits the colourimetric reaction between $\mathrm{CPZ}$ and $\mathrm{Fe}$ (III) ion that occurs at a solid/liquid interface, the solid layer consisting of ferric iron entrapped in a layer of plasticized PVC. If solutions containing $\mathrm{CPZ}$ are dropped onto such a layer, a colour change occurs from light yellow to dark pink or even light blue, depending on the concentration of CPZ. Visual inspection enables the concentration of CPZ to be estimated. The resulting colouration was also monitored by digital image collection for a more accurate quantification. The three coordinates of the hue, saturation and lightness system were obtained by standard image processing along with mathematical data treatment. The parameters affecting colour were assessed and optimized. Studies were conducted by visible spectrophotometry and digital image acquisition, respectively. The response of the optimized probe towards the concentration of CPZ was tested for several mathematical transformations of the colour coordinates, and a linear relation
\end{abstract}

was found for the sum of hue and luminosity. The limit of detection is $50 \mu \mathrm{M}$ (corresponding to about $16 \mu \mathrm{g}$ per $\mathrm{mL}$ ). The probe enables quick screening for $\mathrm{CPZ}$ in real water samples with prior sample treatment.

Keywords Chlorpromazine Colourimetry - Optical probe Aquaculture

\section{Introduction}

Aquaculture is a vital food source around the world. It provides nutritious and healthy fish and fishery products at low cost. Strong safety policies are applied to these products given that a small mistake may pose a serious risk to an entire population, of acute or long-term effects [1]. Several hazards have been already associated to aquaculture production, including environmental contaminants, unapproved food additives, and improper use of growth hormones or veterinary drugs.

Veterinary drugs employed in aquaculture ensure higher rate benefits within intensive production. They prevent or treat diseases, control parasites, aid reproductive processes, tranquilize fish and promote growth. Some of the drugs are potentially carcinogenic, can cause allergic reactions and may lead to antibiotic resistance in humans [2]. As a consequence, the EU has established regulations that limit or prohibit their use [3].

Chlorpromazine (CPZ) is an example of that. It is phenothiazine derivative employed as an antiemetic, preanaesthetic and muscle relaxant, although it is widely used in humans to treat various mental and personality disorders 
Fig. 1 Schematic illustration for the development of the colour product in the probe

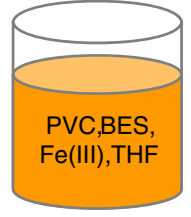

[4]. It is today banned from EU although it is still being used in some occasions [3]. Facing today's regulations, it is important to have methods for on-site screening, as a measure of control of its application.

Several methods have been reported in the literature for CPZ determination. These include spectrofluorimetry [5], chemiluminescence [6], high performance liquid chromatography [7-10], voltammetry [11-13], differential pulse stripping voltammetry [14-17], polarography [18, 19], and electrophoresis [20-24], visible spectrophotometry [25-29] and a combination of the previous ones [30]. These methods exhibit excellent selectivity, but require expensive instrumentation and are unsuitable for screening in the local under survey. An alternative procedure for field evaluations could be a small sensing strip, based on an optical probe (for an easy transportation) and low cost materials (allowing its disposable after use).

In general, the major goals of a possible new method rely on the low coast, easy performance and quick response for a specific target analyte. Although not simple, the idea of developing a "simple" colour screening stick for a home-detection of several drugs is indeed very attractive. This concept has been started here for $\mathrm{CPZ}$.

An important characteristic of phenothiazine derivatives is their easy oxidation in acidic medium and subsequent formation of coloured oxidation products [31]. Several oxidants such as $\mathrm{Fe}^{3+},\left[\mathrm{Fe}(\mathrm{CN})_{6}\right]^{3-}, \mathrm{Cr}_{2} \mathrm{O}_{7}{ }^{2-}, \mathrm{IO}_{3}{ }^{-}, \mathrm{IO}_{4}{ }^{-}$, $\mathrm{BrO}_{3}{ }^{-}, \mathrm{H}_{2} \mathrm{O}_{2}$, have been reported for this purpose, being iron and its anionic complexes the most used ones [3234]. $\mathrm{FeCl}_{3}$ is the elected reagent due to the high stability of the intermediate radicals formed. The optical probe is designed by immobilizing iron on a PVC membrane containing bis(2-ethylhexyl)sebacate (BES) as plasticizer, deposited over a polycarbonate solid support. The contact of CPZ with the immobilized iron grants its oxidation and the subsequent formation of a coloured product detected by human eye. This principle may guide to a new generation of portable colourimetric sensing strips for rapid drug screening in real samples, capable of a routine environmental use.

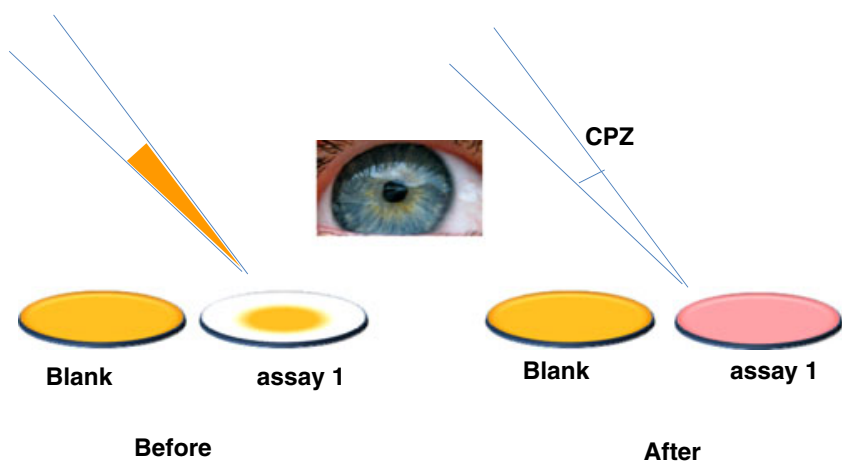

\section{Experimental}

Apparatus

All spectrophotometric measurements were carried out at room temperature using a double beam Spectrophotometer Thermo Evolution 300 UV-Visible with $1 \mathrm{~cm}$ length plastic cells. The digital image of solid surfaces was acquired by a digital camera Olympus C-480 with 4 megapixels, and $3 \times$ optical zoom lens,. The Paint program of windows 2007 was used for gaining the three coordinates of the HSL model system. Polycarbonate plates (Kartell) of eight cavities and of $200 \mu \mathrm{L}$ each were used for deposition of the sensory material.

\section{Reagents}

All chemicals were of analytical grade and de-ionized water (conductivity $<0.1 \mu \mathrm{S} \mathrm{cm}^{-1}$ ) was employed. CPZ, bis(2ethyllhexyl)sebacate (BES) and poly (vinyl chloride) (PVC) of high molecular weight were purchased from Fluka

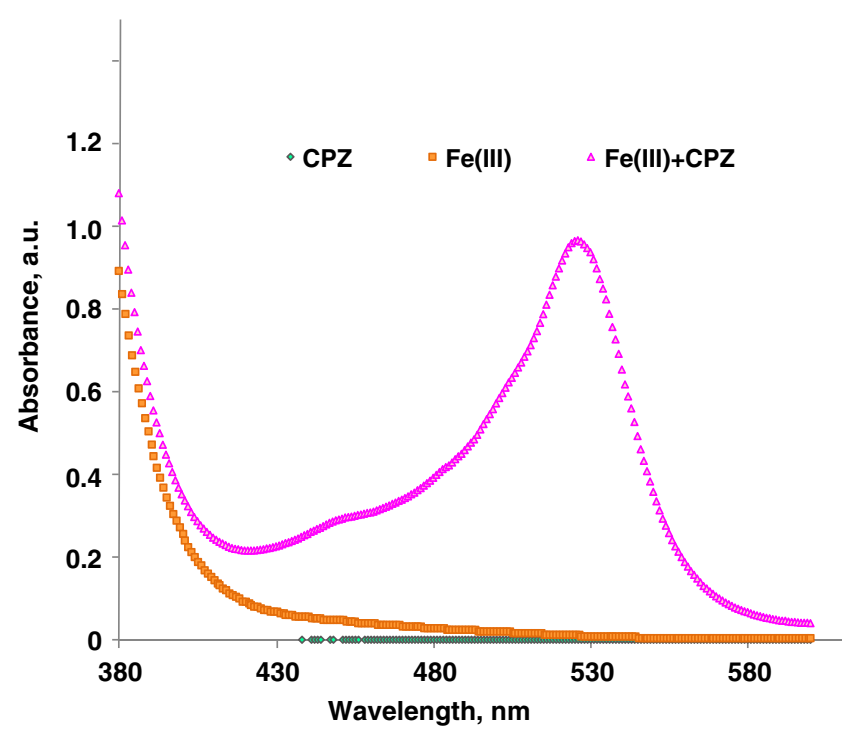

Fig. 2 Spectra of CPZ, Fe(III) and the formation product between both 
(www.sigmaaldrich.com). Tetrahydrofuran (THF) was obtained from Panreac (www.panreac.es). Iron (III) chloride hexahydrate was purchased by Merck (www.merck-chemicals. com.pt) and HEPES from Sigma (www.sigmaaldrich.com/ chemistry.html).

Optical single-short probe preparation

The optical single-short probe was prepared by mixing variable amounts of $\mathrm{FeCl}_{3}$ with $0.050 \mathrm{~g}$ of $\mathrm{PVC}$, and $0.100 \mathrm{~g}$ of plasticizer BES. The mixture was stirred until the PVC was well moistened, and dispersed in $2 \mathrm{~mL}$ of THF. A volume of $50 \mu \mathrm{L}$ of each of these solutions was casted on each cavity of the polycarbonate plate and let dry for $30 \mathrm{~min}$ (Fig. 1).

Procedures in liquid phase

\section{Wavelength selection}

The coloured complex formed between $\mathrm{Fe}$ and $\mathrm{CPZ}$ was investigated by recording the spectra of individual and mixed components. Solutions of $6.7 \times 10^{-3} \mathrm{~mol} \mathrm{~L}^{-1} \mathrm{Fe}(\mathrm{III})$, $3.0 \times 10^{-4} \mathrm{~mol} \mathrm{~L}^{-1} \mathrm{CPZ}$ and a mixture of both (1:1) were used for this purpose. These solutions were prepared in variable $\mathrm{pHs}$ (acidic, neutral and alkaline) by addition of a few drops of saturated sodium hydroxide or hydrochloric acid solutions. Maximum absorbancies were obtained for $526 \mathrm{~nm}$, in acidic medium, and further quantification studies were carried out in this wavelength.

pH effect

The $\mathrm{CPZ}$ and $\mathrm{Fe}(\mathrm{III})$ solutions were prepared in $1.00 \times 10^{-2}$ and $1.00 \times 10^{-3} \mathrm{~mol} \mathrm{~L}^{-1}$ HEPES buffer solutions, respectively. The final $\mathrm{pH}$ of this solution was adjusted from 1 to 12 , by the addition of suitable amounts of saturated sodium hydroxide or concentrated hydrochloric solutions. A calibration curve from $1.66 \times 10^{-5}$ to $5.81 \times 10^{-4} \mathrm{~mol} \mathrm{~L}^{-1} \mathrm{CPZ}$ was traced for each $\mathrm{pH}$ condition. The concentration of $\mathrm{Fe}$ (III) was kept constant in all experiments, always $3.35 \times$ $10^{-3} \mathrm{~mol} \mathrm{~L}^{-1}$.

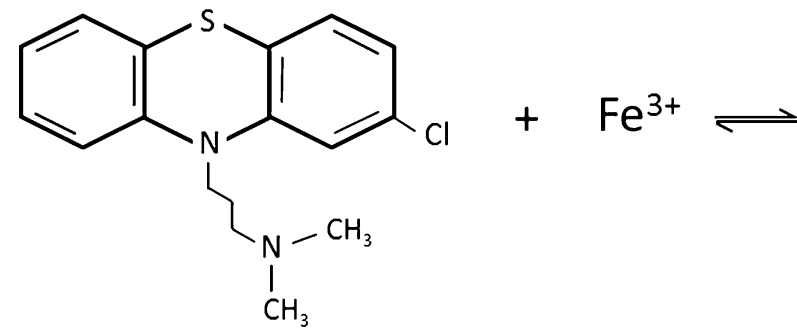

\section{$\mathrm{FeCl}_{3} / \mathrm{CPZ}$ ratio}

The Fe(III) concentration was studied for $\mathrm{pHs} 3$ and 9 and a $3.04 \times 10^{-4} \mathrm{~mol} \mathrm{~L}^{-1} \mathrm{CPZ}$ solution. The concentration of $\mathrm{Fe}$ (III) was varied between $6.67 \times 10^{-4}$ to $2.00 \times 10^{-2} \mathrm{~mol} \mathrm{~L}^{-1}$. All absorbances were measured for $526 \mathrm{~nm}$.

\section{Complex stability}

The stability of the colour oxidation product was investigated by measuring the absorbance for $16 \mathrm{~h}$. The solutions were prepared at $\mathrm{pH} 3$ and 9. The CPZ concentration was $3.04 \times 10^{-4} \mathrm{~mol} \mathrm{~L}^{-1}$ and the $\mathrm{Fe}(\mathrm{III})$ concentration ranged from $3.35 \times 10^{-4}$ to $3.35 \times 10^{-2} \mathrm{~mol} \mathrm{~L}^{-1}$, respectively.

Procedures in solid phase

\section{Analytical procedure}

A volume of $150 \mu \mathrm{L}$ of $\mathrm{CPZ}$ standards ranging from $5.00 \times$ $10^{-5}$ to $1.00 \times 10^{-1} \mathrm{~mol} \mathrm{~L}^{-1}$ or samples was added to each probe on the polycarbonate plate. The blank was the buffer solution and used as control. The colour of the probes were measured by taking their picture with a digital camera and treating the results with the PAINT program of Windows, using the three coordinates of the HSL model: hue, saturation and lightness. These three values were manipulated in order to obtain a linear or second degree function against the CPZ concentration. All measurements corresponded to the average of, at least, three trials.

\section{Optimization procedures}

The study of the amount of $\mathrm{Fe}$ (III) in the membrane was carried out similarly to that described in " $\mathrm{FeCl}_{3} / \mathrm{CPZ}$ ratio". The amount of Fe(III) studied was 0.5 or $0.1 \mathrm{~g}$ for $\mathrm{pH} 3$ or 9 , respectively.

The time required to achieve a constant colour on the surface of the optical probes was studied by monitoring the analytical response for one hour and thirty minutes. The stability to the complex was also evaluated by means of this study.

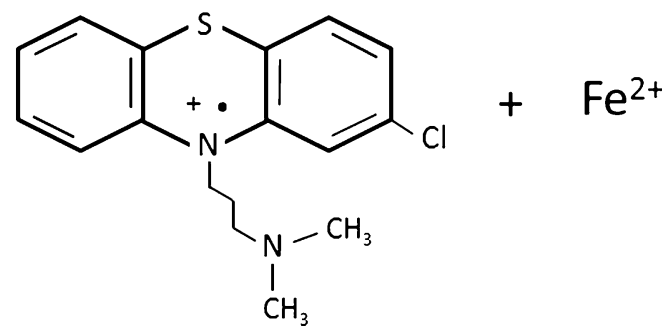

Scheme 1 Oxidation of Chlorpromazine in presence of ferric chloride 
Table $1 \mathrm{pH}$ effect in liquid phase

\begin{tabular}{|c|c|c|c|c|c|c|c|c|}
\hline \multirow[t]{2}{*}{ Parameters } & \multicolumn{8}{|l|}{$\mathrm{pH}$} \\
\hline & 1 & 2 & 3 & 4 & 5 & 7 & 9 & 11 \\
\hline Slope, $\mathrm{L} \mathrm{mol}^{-1} \mathrm{~cm}^{-1}$ & 2229.44 & 1444.13 & 1270.87 & 803.52 & 804.34 & 1519.47 & 942.42 & 933.23 \\
\hline LLLR, $\mathrm{mol} \mathrm{L}^{-1}$ & $8.21 \times 10^{-5}$ & $1.67 \times 10^{-4}$ & $8.42 \times 10^{-5}$ & $8.47 \times 10^{-5}$ & $8.26 \times 10^{-5}$ & $1.65 \times 10^{-5}$ & $8.21 \times 10^{-5}$ & $8.56 \times 10^{-5}$ \\
\hline LSRL, $\mathrm{mol} \mathrm{L}^{-1}$ & $4.92 \times 10^{-4}$ & $5.84 \times 10^{-4}$ & $5.05 \times 10^{-4}$ & $5.08 \times 10^{-4}$ & $4.13 \times 10^{-4}$ & $4.94 \times 10^{-4}$ & $5.75 \times 10^{-4}$ & $5.14 \times 10^{-4}$ \\
\hline$r^{2}$ & 0.9964 & 0.9936 & 0.9978 & 0.9945 & 0.9956 & 0.9966 & 0.9924 & 0.9921 \\
\hline O.O. & 0.207 & 0.237 & 0.123 & 0.179 & 0.141 & 0.105 & 0.210 & 0.266 \\
\hline
\end{tabular}

The effect of $\mathrm{pH}$ was tested by calibrating the optical probe with $\mathrm{CPZ}$ stock solutions of $\mathrm{pH} 3$ or 9.

\section{Determination of $C P Z$ in aquaculture water}

The optical probe was used for the direct determination of $\mathrm{CPZ}$ in water from aquaculture activities. Colour measurements were made by applying the test solution directly over the probe. The results were recorded with a digital camera and the CPZ concentration was calculated using the calibration data.

\section{Results and discussions}

Formation of coloured complex in aqueous media

The formation of the coloured complex was confirmed by recording the visible spectra of single and mixed solutions of Fe(III) and CPZ (Fig. 2). The CPZ solution was unable to absorb radiation from 360 to $750 \mathrm{~nm}$. The Fe(III) solution displayed a light yellow colour, producing little absorbancies within the higher wavelengths; this light colour indicated the presence of $\mathrm{Fe}(\mathrm{OH})^{2+}$ or $\mathrm{Fe}(\mathrm{OH})_{2}{ }^{+}$ species.

A single and strong peak was detected on the spectra of the mixed solution, displaying maximum absorbing properties in $526 \mathrm{~nm}$. The compound behind this peak was probably the radical cation of $\mathrm{CPZ}$, as a result of its oxidation and subsequent $\mathrm{Fe}$ (III) reduction in a 1:1 molar ratio. This mechanism of the redox reaction is shown in Scheme 1.

The obtained absorbancies increased with the CPZ concentration, suggesting a successful application of this system in quantification studies.

\section{$\mathrm{pH}$ effect}

This parameter is very important given that the colour of a specific compound is intrinsically connected to its protonation state. The extent of the reaction leading to the formation of the coloured product and the stability of the formed compound also depend on the $\mathrm{pH}$ [33]. In addition, previous studies using $\mathrm{FeCl}_{3}$ as oxidizing agent indicate an acidic media as the optimal condition for the formation of coloured products $[34,35]$.

The $\mathrm{pH}$ effect was tested by calibrating the system in different buffers, ranging from $\mathrm{pH} 1$ to 11 , with a fixed amount of $\mathrm{Fe}(\mathrm{III})$ and varying concentrations of $\mathrm{CPZ}$ (Figure S1, Electronic Supplementary Material). The resulting calibration data is presented in Table 1. pHs 1 and 2 provided average slopes of 2229 and $1444 \mathrm{~L}$ $\mathrm{mol}^{-1} \mathrm{~cm}^{-1}$, respectively, the highest ones obtained. In terms of lower limit of linear range the behavior was about $8.0 \times 10^{-5} \mathrm{~mol} \mathrm{~L}^{-1}$ in all pHs, except for $\mathrm{pHs} 2$ and 7 . However, high intercepts with Y-axes were obtained for $\mathrm{pHs}$ ranging from 3 to 7 . This resulted from the light yellow colour from iron (III), but this solution could not be used as reference because the concentration of iron (III) varied along each calibration as it was being reduced by CPZ. The higher correlation coefficients were obtained for $\mathrm{pH} 3$, suggesting that the product of the reaction was more stable under this condition. Thus, as a compromise, $\mathrm{pH} 3$ was selected as the best condition in the acidic range.

In alkaline media, both $\mathrm{pH} 9$ and 11 presented similar results however, although smooth, $\mathrm{pH} 9$ display better sensitivity and lower limit of linear range. Compared with the last two $\mathrm{pH}, \mathrm{pH} 7$ presented higher value of lower limit of linear range. For all $\mathrm{pH}$, different behaviors were obtained as show figure $\mathrm{S} 1$. According to the results, $\mathrm{pH}$ 3 in acid and $\mathrm{pH} 9$ in alkaline media were selected for further experiments, once in solution it could exist different ferric species according to $\mathrm{pH}$ that could affect the results.

Table 2 Membrane composition for the optical probe

\begin{tabular}{lll}
\hline Compound & $25 \%$ Iron $(\mathrm{g} / \mathrm{g})$ & $40 \%$ Iron $(\mathrm{g} / \mathrm{g})$ \\
\hline Fe(III) $(\mathrm{g})$ & 0.0509 & 0.1004 \\
PVC $(\mathrm{g})$ & 0.0496 & 0.0531 \\
BES $(\mathrm{g})$ & 0.1069 & 0.1031 \\
THF $(\mathrm{mL})$ & 2 & 2 \\
\hline
\end{tabular}



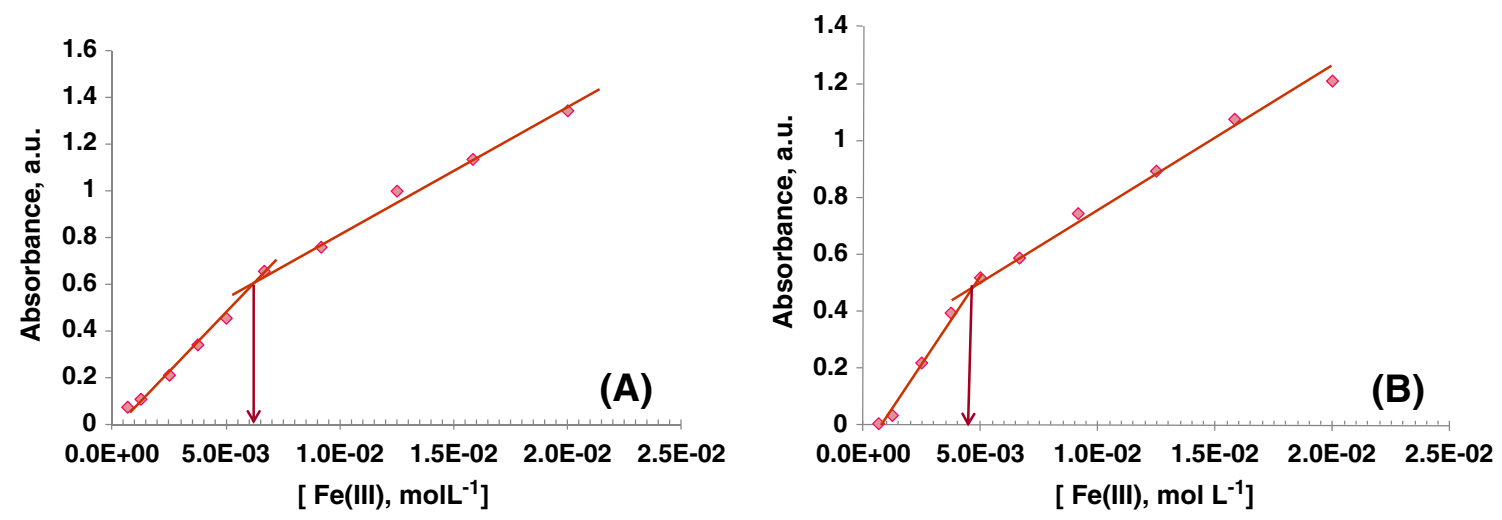

Fig. 3 Effect of molar ratio $\mathrm{Fe}(\mathrm{III}) / \mathrm{CPZ}$ on the coloured complex formation in solution media: (a) $\mathrm{pH} 3$; (b) $\mathrm{pH} 9$

Ratio of $\mathrm{FeCl}_{3} / \mathrm{CPZ}$

All solutions should carry a sufficient amount of Fe(III) to react with all $\mathrm{CPZ}$ molecules present in the solution, up to the maximum $\mathrm{CPZ}$ concentration tested. If the reaction taking place was incomplete, an exceeding amount of reactant would favour the formation of the coloured product. This procedure increases the cost of the determination, for which the amount of $\mathrm{Fe}(\mathrm{III})$ should be set to the minimum required to produce the desired sensitivity.

In the present study, a solution of $3 \times 10^{-4} \mathrm{~mol} \mathrm{~L}^{-1}$ in $\mathrm{CPZ}$ was added of different $\mathrm{Fe}(\mathrm{III})$ concentrations, buffered to the previously selected pHs. Fe(III) concentrations ranged from $3 \times 10^{-4}$ to $2.0 \times 10^{-2} \mathrm{~mol} \mathrm{~L}{ }^{-1}$, corresponding to $\mathrm{Fe}(\mathrm{III}) / \mathrm{CPZ}$ ratios from 1 to 67 . In all cases, the colour formation was immediate and quite stable along time. Not at all expected, $\mathrm{Fe}(\mathrm{III}) / \mathrm{CPZ}$ ratios up to 4 gave light blue solutions that changed to pink with higher amounts of $\mathrm{Fe}$ (III). Thus, the kind of colour obtained could work as an indicator of the concentration level present in a given sample.

The experimental data showed that an increasing amount of $\mathrm{Fe}$ (III) increased the absorbance of the resulting solution

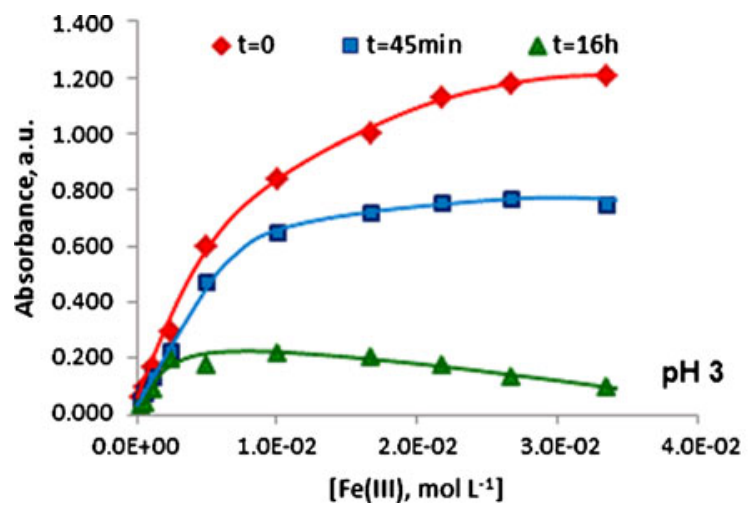

Fig. 4 Stability of the coloured complex during $16 \mathrm{~h}$ in solution media up to a maximum of about 1200 m.a.u. (Fig. 3). This plateau was never observed for lower concentration ratios, down to 0.1 .

The intercept of the two linear regions displayed in Fig. 3 is the best concentration for Fe(III). For pH 3 a $5.8 \times$ $10^{-3} \mathrm{~mol} \mathrm{~L}^{-1}$ concentration was selected, corresponding to a molar ratio $\mathrm{Fe}(\mathrm{III}) / \mathrm{CPZ}$ of 20 . For $\mathrm{pH} 9$ the $\mathrm{Fe}(\mathrm{III})$ concentration was set to $4.5 \times 10^{-3} \mathrm{~mol} \mathrm{~L}^{-1}$, corresponding to a molar ratio $\mathrm{Fe}(\mathrm{III}) / \mathrm{CPZ}$ of 14 . These great excess if iron required confirmed that the reaction was incomplete. Similar results were obtained for different times up to 30 min after mixing the reagents, thus suggesting that the reaction was in equilibrium or that the formed product was stable for a long time.

\section{Complex stability}

The stability of the complex was studied by measuring the absorbances of all calibrating solutions (from $3.35 \times 10^{-4}$ to $3.35 \times 10^{-2} \mathrm{~mol} \mathrm{~L}^{-1}$ ) for $16 \mathrm{~h}$. Studies were conducted for pHs 3 and 9 and the results are plotted in Fig. 4.

A similar behaviour was obtained in both pHs. The colour was formed immediately after mixing Fe(III) and

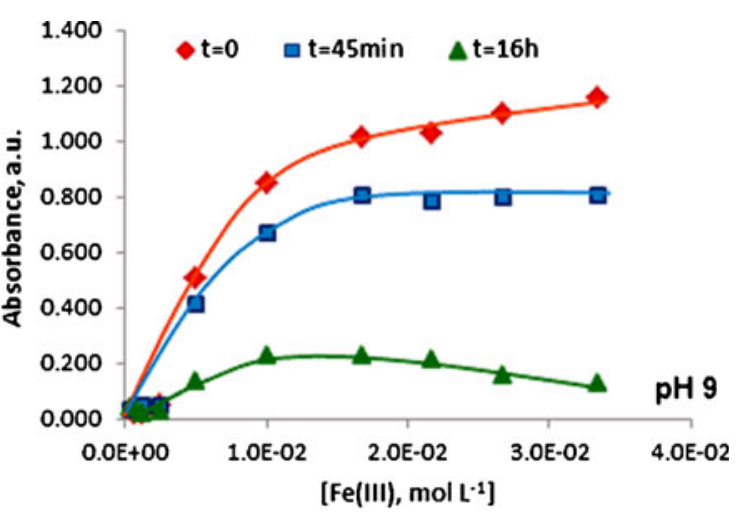




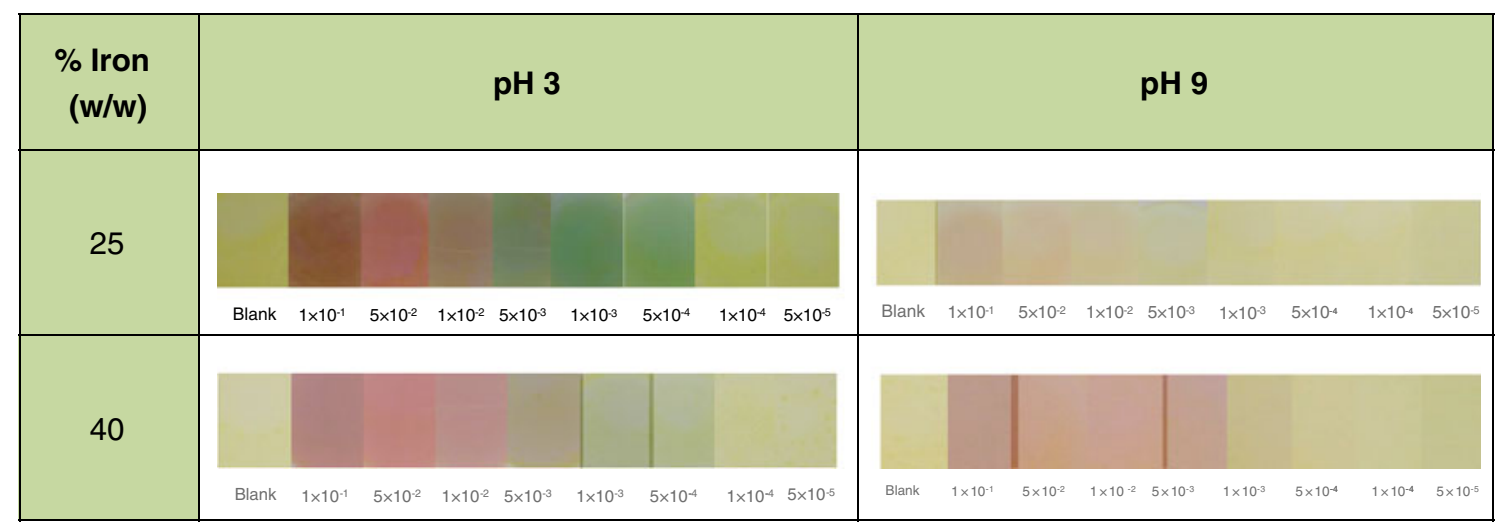

Fig. 5 Influence of $\mathrm{pH}$ and $\mathrm{Fe}(\mathrm{III})$ amount on the coloured complex formation in a solid matrix

CPZ. Maximum absorbances were therefore obtained at time zero. The absorbance was not stable for $30 \mathrm{~min}$, decreasing with a slow rate. A faster decreased was observed afterwards and by the end of $16 \mathrm{~h}$ the absorbance of the complex was very low.

Curiously, the product formed in a $\mathrm{pH} 3$ environment was a little less stable within time than that obtained in $\mathrm{pH}$ 9.

Preparation of the optical single-short probe

The optical probe was prepared by entrapping Fe(III) on a polymeric matrix. Plasticized PVC was selected for this purpose because it is inert to both $\mathrm{CPZ}$ and iron and allows ion-exchange on the solid/liquid interface. In addition, it is of low cost and compatible with most materials that may constitute the physical support of the probe, such as ceramics and regular plastics.

Knowing that the amount of $\mathrm{Fe}(\mathrm{III}), \mathrm{pH}$ and time may turn out crucial parameters, these were finely studied under solid state.

$\mathrm{Fe}(\mathrm{III})$ load and $\mathrm{pH}$

The previous studies have indicated the need to control the $\mathrm{pH}$ and ensure an exceeding amount of $\mathrm{Fe}(\mathrm{III})$, conditions with great impact on the detection limit of the probe. There is however a physical limit for doping a PVC membrane with a solid species and preserving its mechanical integrity and exchange capability. In addition, the higher the iron amount, the more intense was the yellow colour of the blank membrane.

Two doping levels of Fe(III) for pHs 3 and 9 were tested (Table 2): $25 \%$ or $40 \%(\mathrm{w} / \mathrm{w})$, the later being the maximum loading percentage possible. Visual inspection indicated that the membrane with higher amount of $\mathrm{Fe}$ (III) presented more intense colours, including that of the blank membrane. Each membrane was used to make a calibration curve with stock solutions of CPZ ranging from to $5 \times 10^{-5}$ to $1 \times 10^{-1} \mathrm{~mol} \mathrm{~L}^{-1}$ and was also made a membrane as a blank. For the higher concentrations of CPZ the membrane changed to dark pink colour while the low concentrations gave a light blue (Fig. 5).

The colour gradient was more intense for membranes with a higher amount of $\mathrm{Fe}(\mathrm{III})$. This was confirmed by both visual and digital inspections, in pHs 3 and 9 . Regarding digital acquisition, several three-dimensional representations of a specific colour could represent useful properties of that colour, but only the application determines which would be the most reliable. In the present study, and with the purpose of giving a simple way of measuring in almost any place, the HSL model in programs from Windows was selected. Several mathematical approaches were made over the three coordinates to reach
Table 3 Influence of $\mathrm{pH}$ and ion(III) amount in the probe

\begin{tabular}{|c|c|c|c|c|}
\hline \multirow[t]{2}{*}{ Parameters } & \multicolumn{2}{|c|}{$25 \%$ Iron $(\mathrm{g} / \mathrm{g})$} & \multicolumn{2}{|c|}{$40 \%$ Iron $(\mathrm{g} / \mathrm{g})$} \\
\hline & $\mathrm{pH} 3$ & $\mathrm{pH} 9$ & $\mathrm{pH} 3$ & $\mathrm{pH} 9$ \\
\hline Slope & 13.64 & 10.17 & 24.02 & 15.67 \\
\hline LLLR, $\mathrm{mol} \mathrm{L}^{-1}$ & $5.01 \times 10^{-5}$ & $5.01 \times 10^{-4}$ & $5.01 \times 10^{-5}$ & $1.00 \times 10^{-4}$ \\
\hline LSRL, $\mathrm{mol} \mathrm{L}^{-1}$ & $1.00 \times 10^{-1}$ & $1.00 \times 10^{-1}$ & $1.00 \times 10^{-1}$ & $1.00 \times 10^{-1}$ \\
\hline$r^{2}$ & 0.8820 & 0.8592 & 0.9529 & 0.9170 \\
\hline Intercept, a.u. & 66.12 & 40.24 & 113,91 & 69,68 \\
\hline
\end{tabular}


Table 4 Stability results according to $\mathrm{pH}$ and Fe(III) amount during $90 \mathrm{~min}$

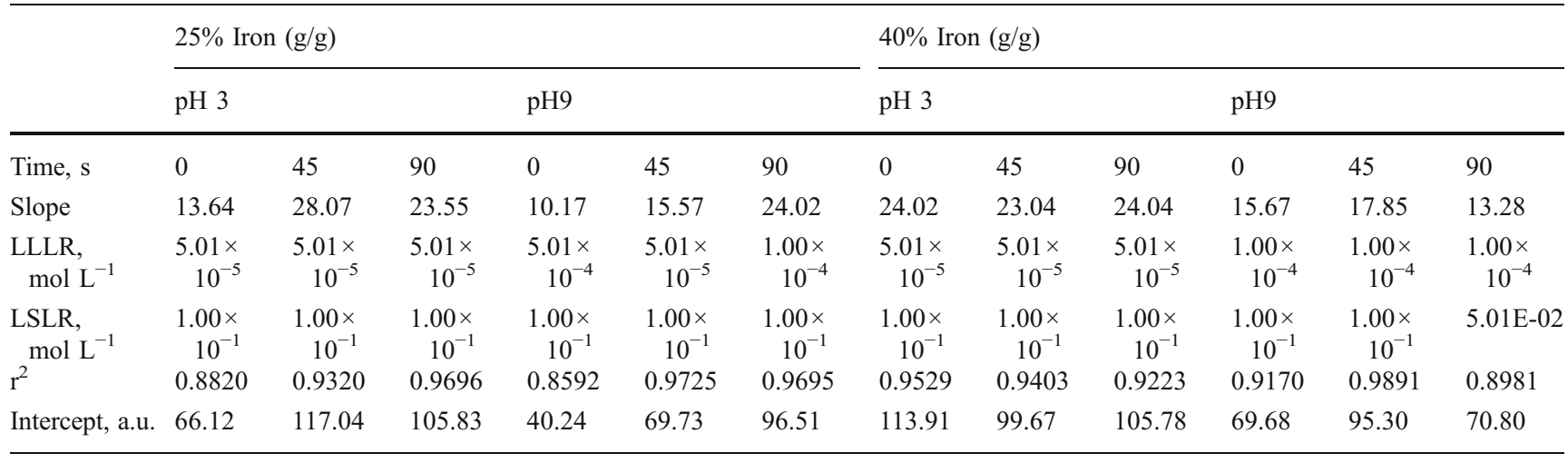

a simple correlation between the true and known variable (concentration, in $\mathrm{X}$ axis) and the analytical signal (in $\mathrm{Y}$ axis). In almost all cases, this was achieved by plotting the sum of hue and luminosity against logarithm concentration. The $\mathrm{Y}$ axis was considered as arbitrary units while the concentration was expressed in mol L ${ }^{-1}$.

The general analytical features of the prepared optical single-short probe are indicated in Table 3. The membranes working in $\mathrm{pH} 3$ displayed linear ranges from $5 \times 10^{-5}$ to $1 \times 10^{-1} \mathrm{mo} \mathrm{L}^{-1}$. The $40 \%$ load in Fe(III) gave the highest slopes, double to those observed in $25 \%$. Similar behaviour was observed for $\mathrm{pH} \mathrm{9,} \mathrm{with} \mathrm{the} \mathrm{membranes} \mathrm{of} \mathrm{higher} \mathrm{Fe}$ (III) load giving higher sensitivity and better linear ranges $\left(1 \times 10^{-4}\right.$ against $\left.5 \times 10^{-4} \mathrm{~mol} \mathrm{~L}^{-1}\right)$.

In general terms, the highest load in Fe(III) favoured the analytical features of the sensing membrane for increasing the amount of reaction product. The best analytical performance was reached when $\mathrm{CPZ}$ was prepared in acid media. This was confirmed by the literature, because the radical products from the iron/CPZ redox reaction were stabilized by acidic conditions.

\section{Reading time}

Although the complex is stable for a long period, the CPZ molecule in a liquid phase must meat $\mathrm{Fe}(\mathrm{III})$ on a solid phase for reaction to take place. CPZ has to reach the solid membrane where the iron is entrapped or find leached iron in the liquid phase. This means that some additional time may be required to achieve maximum colour. The intensity of the colour of the optical single-short probe was tested for $90 \mathrm{~min}$.

Membranes with lower amounts of $\mathrm{Fe}$ (III) covered with solutions of $\mathrm{pH} 3$ showed colours of increased intensity up to $45 \mathrm{~min}$, and after that time the colour started fading away. For $\mathrm{pH} 9$ the colour intensity kept increasing until the $90 \mathrm{~min}$. This increase was not however proportional in all standards, narrowing the linear range.

Membranes of higher iron load and tested in solutions of $\mathrm{pH} 3$ displayed almost immediately their final colour. This colour was stable along the $90 \mathrm{~min}$. For $\mathrm{pH} 9$, the colour intensity of the complex increased slightly until $45 \mathrm{~min}$, decreasing after that. Thus, colour measurement should be conducted before $45 \mathrm{~min}$ for the present membranes.

\section{Determination of $\mathrm{CPZ}$ in aquaculture water}

The best optical probe was applied to determine CPZ in aquaculture water: higher iron loads $(40 \% \mathrm{~g})$ and tested in $\mathrm{pH}$ 3. Blank water samples were spiked of $5.0 \times 10^{-4}$. Visual inspection allowed confirming the low concentration because the colour formed was light blue. The analytical results confirmed the accuracy and precision of the screening probe for the lower concentration range (Table 4). Thus, the probe may be used to screen CPZ in low concentrations $\left(\approx 150 \mu \mathrm{g} \mathrm{mL}^{-1}\right)$ (Table 5).

Table 5 Colourimetric determination of $\mathrm{CPZ}$ in aquaculture samples with the optical probe

\begin{tabular}{|c|c|c|c|c|c|c|}
\hline \multirow[t]{2}{*}{ Sample } & \multirow[t]{2}{*}{$\mathrm{CPZ}, \mathrm{mol} \mathrm{L}^{-1}$} & \multirow[t]{2}{*}{$\log$ Conc. CPZ } & \multicolumn{4}{|c|}{ Found, mol L ${ }^{-1}$} \\
\hline & & & Solid sensor & Average & Standard deviation & Relative Error, \% \\
\hline \multirow[t]{3}{*}{ Aquaculture 1} & \multirow[t]{3}{*}{$5.00 \times 10^{-4}$} & \multirow[t]{3}{*}{-3.30} & $5.72 \times 10^{-4}$ & \multirow[t]{3}{*}{$6.10 \times 10^{-4}$} & \multirow[t]{3}{*}{$8.67 \times 10^{-9}$} & 12.56 \\
\hline & & & $6.86 \times 10^{-4}$ & & & 27.11 \\
\hline & & & $5.72 \times 10^{-4}$ & & & 12.56 \\
\hline
\end{tabular}




\section{Conclusions}

In this work an optical probe for quick screening CPZ was developed by incorporating iron in a PVC plastic membrane. Surface colour change was easily achieved by naked eye. The resulting colour intensity observed by a digital camera was directly proportional to $\log$ of $\mathrm{CPZ}$ concentration. The use of Fe(III) in higher amounts, as well as the preparation of $\mathrm{CPZ}$ solution in $\mathrm{pH} 3$ enhanced the intensity of the determination. Measurements should be conducted before $45 \mathrm{~min}$ after the beginning of the reaction to assure high signals.

This work allowed the rapid screening of CPZ and shows strong potential for field applications. However its detection limit is not low enough for a direct analysis of the samples. Therefore, further tests should be conducted to improve this parameter. This should start by attaching Fe (III) to nanoparticles bound to the outer layer of a polymeric membrane, increasing the contact area and, consequently, decreasing the detection limit.

Acknowledgements The authors acknowledge the financial support from FCT, Fundação para a Ciência e Tecnologia/FEDER, by means of project PTDC/AGR-AAM/68359/2006.

\section{References}

1. Guidelines for risk-based fish inspection (2009) Food Agriculture Organization (FAO). Food and nutrition Paper 90 Rome: FAO.

2. Huss HH (2003) Assessment and management of seafood safety and quality. Food Agriculture Organization (FAO). Fisheries Technical Paper 444.Rome: FAO.

3. Commission Regulation 37/2010 Commission Regulation (EU) No $37 / 2010$ of 22 December 2009 on pharmacologically active substances and their classification regarding maximum residue limits in foodstuffs of animal origin, Off. J. Eur. Uniao. L 15/1 (2010).

4. Karpinska J, Starczewska B, Puzanowska-Tarasiewicz H (1996) Analytical properties of 2- and 10-disubstituted phenothiazines derivatives. Anal Sci 12:161

5. White VR, Frings CS, Villafranca JE, Fitzgerald JM (1976) Rapid fluorimetric determination of phenothiazines employing in situ photochemical oxidation. Anal Chem 48:1314

6. Kojlo A, Michalowski J, Wolyniec E (2000) Chemiluminescence determination of thioridazine hydrochloride by flow-injection analysis. J Pharm Biomed Anal 22:85

7. De Orsi D, Gagliardi L, Tonelli D (1996) High performance liquid chromatographic determination of promazine in pharmaceutical formulations. J Pharm Biomed Anal 14:1635

8. Wallace JE, Shimek EL, Stavchansky S, Harris SC (1981) Determination of promethazine and other phenothiazine compounds by liquid chromatography with electrochemical detection. Anal Chem 53:960

9. Saracino MA, Amore M, Baioni E, Petio C, Raggi MA (2008) Determination of selected phenothiazines in human plasma by solid-phase extraction and liquid chromatography with coulometric detection. Anal Chim Acta 624:308
10. Tanaka E, Nakamura T, Terada M, Shinozuka T, Hashimoto C, Kurihara K, Honda K (2007) Simple and simultaneous determination for 12 phenothiazines in human serum by reversed-phase high-performance liquid chromatography. J Chromatogr B 854:116

11. Zimova N, Nemec I, Zima J (1986) Determination of chlorpromazine and thioridazine by differential pulse voltammetry in acetonitrile medium. Talanta 33:467-470

12. Lukasiewicz M (2008) Electrochemical oxidation of phenothiazine derivatives at glassy carbon electrode and their differential pulse and square-wave voltammetric determination in pharmaceuticals. Anal Lett 41:789

13. Ensafi A, Heydari E (2008) Determination of some phenothiazines compounds in pharmaceuticals and human body fluid by electrocatalytic oxidation at a glassy carbon electrode using methylene blue as a mediator. Anal Lett 41:2487

14. Dermis S, Biryol I (1989) Voltammetric determination of chlorpromazine hydrochloride. Analyst 114:525

15. Bishop E, Hussein W (1984) Electroanalytical studies of phenothiazine neuroleptics at gold and platinum electrodes. Analyst 109:229

16. Wang J, Freiha BA (1983) Substractive differential pulse voltammetry following adsorptive accumulation of organic compounds. Talanta 30:837

17. Ni Y, Wang L, Kokot S (2001) Voltammetric determination of chlorpromazine hydrochloride and promethazine hydrochloride with the use of multivariate calibration. Anal Chim Acta 439:159

18. Belal F, El-Ashry SM, Shehata IM, El-Sherbeny MA, El-Sherbeny DT (2000) Differential pulse polarographic determination of some $\mathrm{N}$-substituted phenothiazine derivatives in dosage forms and urine through treatment with nitrous acid. Mikrochim Acta 135:147

19. Wang F, Khaledi MG (1996) Chiral separations by nonaqueous capillary electrophoresis. Anal Chem 68:3460

20. Muijsclaar PGHM, Claessens HA, Cramers CA (1996) Determination of structurally related phenothiazines by capillary zone electrophoresis and micellar electrokinetic chromatography. J Chromatogr 735:395

21. Li JG, Zhao FJ, Ju HX (2006) Simultaneous determination of psychotropic drugs in human urine by capillary electrophoresis with electrochemiluminescence detection. Anal Chim Acta 575:57

22. Wang R, Lu X, Wu M, Wang E (1999) Separation of promethazine and thioridazine using capillary electrophoresis with end-column amperometric detection. J Chromatogr B 721:327

23. Wang RY, Lu XN, Wu MJ (2001) Chiral separation of promethazine by capillary electrophoresis with end-column amperometric detection. J Sep Sci 24:658-662

24. Basavaiah K, Krishnamurthy G (1999) Spectrophotometric determination of some phenothiazine drugs acting on the central nervous system using hexacyanoferrate(III). Ann Chim 89:623

25. Elansary AL, Elhawary WF, Issa YM, Ahmed AF (1999) Application of ion-pairs in pharmaceutical analysis. Atomic absorption spectrometric determination of promazine, chlorpromazine, promethazine, imipramine and ciprofloxacin hydrochlorides with sodium cobaltinitrite. Anal Lett 32:2255

26. Kitamura K, Goto T, Kitade T (1998) Talanta 46:1433

27. Karpińska J, Kojlo A, Grudniewska A, Puzanowska-Tarasiewicz $\mathrm{H}$ (1996) The improved flow-injection method for the assay of phenothiazine neuroleptics in pharmaceutical preparations using Fe(III) ions. Pharmazie 51:950

28. Revanasiddappa HD, Ramappa PG (1996) Spectrophotometric determination of some phenothiazine drugs. Talanta 43:1291

29. Hayen H, Karst U (2003) Analysis of phenothiazine and its derivatives using LC/electrochemistry/MS and LC/electrochemistry/fluorescence. Anal Chem 75:4833

30. Gupta RR (1988) Phenothiazines and 1, 4-benzothiazines:chemical and biomedical aspects. Bioactive Molecules 4:861 
31. Puzanowska-Tarasiewicz H, Karpinska J, Kuzmicka L (2009) Analytical applications of reactions of Iron(III) and Hexacyanoferrate(III) with 2,10-disubstituted phenothiazines. Int $\mathrm{J}$ Anal Chem 2009:8

32. Puzanowska-Tarasiewicz H, Karpinska J (2003) Analytical studies and application of reaction of promazine and thioridazine hydrochlorides with some oxidants. Acta Poloniae Pharm 60:409
33. Misiuk W, Kuzmicka L, Mielech K, Puzanowska-Tarasiewicz H (2001) Examination of iron (III) and hexacyanoferrate (III) ions as reagents for the spectrophotometric determination of promazine and perazine. Acta Poloniae Pharm 58:421

34. Jelınek I, Nemcova I, Rychlovsky P (1991) Effects of salts on the stability of the cationic radical of phenothiazine derivatives. Talanta 38:1309 